\title{
Fabrication of vertically aligned single-crystalline lanthanum hexaboride nanowire arrays and investigation of their field emission
}

\author{
Junqi Xu${ }^{1,2}$, Guanghua Hou ${ }^{2}$, Huiqiao $\mathrm{Li}^{1}$, Tianyou Zhai ${ }^{1}$, Baoping Dong ${ }^{2}$, Hailong Yan $^{2}$, Yanrui Wang ${ }^{2}$, \\ Benhai $\mathrm{Yu}^{2}$, Yoshio Bando ${ }^{3}$ and Dmitri Golberg ${ }^{3}$
}

High-quality, uniform, one-dimensional (1D) lanthanum hexaboride $\left(\mathrm{LaB}_{6}\right)$ nanostructures with different morphologies (for example, sparse or dense nanoneedles, or nanorods and nanowire arrays) were fabricated through an effective, easily controlled, one-step, catalyst-free chemical vapor deposition process. The morphologies, structures and temperature-dependent field emission (FE) properties were systematically investigated. FE measurements at room temperature (RT) showed that LaB $_{6}$ nanowire arrays possess the best FE characteristics among all $1 \mathrm{D} \mathrm{LaB}_{6}$ nanostructures, with a low turn-on electric field $\left(E_{\mathrm{to}}, 1.82 \mathrm{~V}_{\mu \mathrm{m}}{ }^{-1}\right)$, a low threshold electric field $\left(E_{\mathrm{thr}}, 2.48 \mathrm{~V}_{\mu \mathrm{m}^{-1}}\right)$, a high current $\left(5.66 \mathrm{~mA} \mathrm{~cm}^{-2}\right.$ at $\left.2.92 \mathrm{~V}_{\mu \mathrm{m}}{ }^{-1}\right)$ and good stability (at a testing time of $1000 \mathrm{~min}$, fluctuations were $<6.0 \%$ ). Temperature-dependent FE showed that the turn-on and

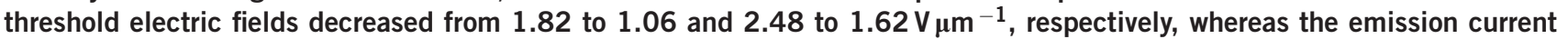
density increased significantly from 0.20 to $9.05 \mathrm{~mA} \mathrm{~cm}^{-2}$ at $2.20 \mathrm{~V} \mu \mathrm{m}^{-1}$ when the temperature was increased from RT to $723 \mathrm{~K}$. The emission current density and the dependence of the effective work function on temperature were also investigated. We attribute the significant reduction of the turn-on and threshold fields and the remarkable increase of emission current to a decrease in the effective work function with temperature.

NPG Asia Materials (2013) 5, e53; doi:10.1038/am.2013.25; published online 12 July 2013

Keywords: arrays; field emission; $\mathrm{LaB}_{6}$; nanowires; temperature-dependent

\section{INTRODUCTION}

Cathode-nanostructured materials are significant in the field of electronics, particularly in flat panel displays, electron microscopes and X-ray sources. Field emission (FE) is a quantum mechanical tunneling phenomenon in which electrons are emitted from the surface of the material to a vacuum under an applied external electric field. Numerous one-dimensional (1D) materials, including carbon nanotubes $\left(\mathrm{CNTs}^{1}\right)$, oxides $\left(\mathrm{ZnO},{ }^{2} \mathrm{WO}_{\mathrm{x}}{ }^{3}\right)$, carbides $\left(\mathrm{SiC}^{4}\right)$, nitrides $\left(\mathrm{AlN},{ }^{5} \mathrm{GaN}^{6}\right)$ and metals $\left(\mathrm{W}^{7}\right)$, have been comprehensively studied as candidates for FE applications. Among these materials, CNTs and oxide nanowires have exhibited excellent FE performances characterized by relatively low turn-on fields, a high current density and a high enhancement factor. However, higher work functions (the work functions are all $>4.0 \mathrm{eV}$ for the materials considered), uncontrolled structures (especially chiralities in $\mathrm{CNTs}^{8}$ ), the lack of adequate long-term and/or high-temperature FE stabilities and unsatisfactory mechanical properties have hindered the development of these materials for practical applications. ${ }^{7}$ The Fowler-Nordheim (F-N) theory ${ }^{9}$ predicts that electron emitters made of materials with a low-work function and a high aspect ratio can greatly enhance an FE current and lower the needed turn-on voltage. Therefore in addition to improving the FE properties of the CNTs and oxide nanostructures, developing and searching for new materials (that is, the low-work function materials) have attracted a considerable interest from both fundamental and practical viewpoints.

Lanthanum hexaboride $\left(\mathrm{LaB}_{6}\right)$ brings together a unique combination of all desired properties required for excellent cathode materials: low-work function $(2.6 \mathrm{eV})$, low volatility at high temperatures, high brightness, high chemical resistance and high mechanical strength. ${ }^{10-15}$ Thus, $1 \mathrm{D} \mathrm{LaB}_{6}$ nanostructures should be an ideal candidate for $\mathrm{FE}$ applications, especially if $\mathrm{LaB}_{6}$ nanostructures have

${ }^{1}$ State Key Laboratory of Material Processing and Die and Mould Technology, School of Material Sciences and Engineering, Huazhong University of Science and Technology (HUST), Wuhan, PRC; ${ }^{2}$ Key Laboratory of Advanced Micro/Nano Functional Materials, Department of Physics and Electronic Engineering, Xinyang Normal University, Xinyang, PRC and ${ }^{3}$ International Center for Materials Nanoarchitectonics (WPI-MANA), National Institute for Materials Science (NIMS), Namiki 1-1, Tsukuba, Ibaraki, Japan

Correspondence: Professor T Zhai, State Key Laboratory of Material Processing and Die \& Mould Technology, School of Materials Science and Engineering, Huazhong University of Science and Technology (HUST), Wuhan 430074, PRC.

E-mail: zhaity@hust.edu.cn

or Professor J Xu, Key Laboratory of Advanced Micro/Nano Functional Materials, Department of Physics and Electronic Engineering, Xinyang Normal University(XYNU), Xinyang 464000, PRC.

E-mail: xujunqi@yahoo.cn

Received 14 December 2012; revised 6 April 2013; accepted 15 April 2013 
an elongated geometry and sharp emitting tips. Zhang et al. ${ }^{10}$ have demonstrated room temperature (RT) FE of a single $\mathrm{LaB}_{6}$ nanowire with a current density as high as $5 \times 10^{5} \mathrm{~A} \mathrm{~cm}^{-2}$ at a working voltage of $800 \mathrm{~V}$, which is one order of magnitude higher compared with that of the state-of-the-art $\mathrm{W} / \mathrm{ZrO}$ thermal field emitters working at $1800{ }^{\circ} \mathrm{C}$ with a $3-\mathrm{kV}$ extraction voltage. An individual $\mathrm{LaB}_{6}$ nanowire also shows an emission current density comparable to that of an individual $\mathrm{C}$ nanotube with a diameter 10-50 times smaller. However, the fabrication of $1 \mathrm{D} \mathrm{LaB}_{6}$ nanostructures is still challenging. For example, a large number of experiments indicate that the traditionally effective methods, such as solid-state reactions, borothermal reduction processes, thermal evaporation and hydrothermal reaction, are not suitable for the growth of high-aspect-ratio $1 \mathrm{D} \mathrm{LaB}_{6}$ nanostructures. Recently, Zhang et al. ${ }^{11-13}$ and Xu et al. ${ }^{14}$ synthesized $\mathrm{LaB}_{6}$ nanowires using $\mathrm{BCl}_{3}$ as a boron precursor; but in the application of this method, it was difficult to obtain large-area, high-quality $\mathrm{LaB}_{6}$ nanostructures. This difficulty might be attributed to the inherent properties of the boron precursor (that is, $\mathrm{BCl}_{3}$ is not an effective boron precursor, ${ }^{16}$ and strong corrosion of $\mathrm{BCl}_{3}$ can damage the surface of the substrates and the nanowires produced at high temperatures). Brewer et al. ${ }^{15}$ reported an effective chemical vapor deposition (CVD) method to synthesize $\mathrm{LaB}_{6}$ nanoobelisks by using $\mathrm{LaCl}_{3}$ and $\mathrm{B}_{10} \mathrm{H}_{14}$ as the starting materials and platinum $(\mathrm{Pt})$ or gold $(\mathrm{Au})$ as the catalysts. The problem with this method is that on the one hand, $\mathrm{B}_{10} \mathrm{H}_{14}$ is a solid precursor and it is not easy to control its flow under CVD; control of its flow under CVD would require external heating devices and complex pipelines into the reactor. On the other hand, the utilization of $\mathrm{Pt}$ and $\mathrm{Au}$ catalysts would greatly limit the large-scale production of $\mathrm{LaB}_{6}$ nanowires owing to the cost. Investigation of a simpler, more effective method to synthesize $\mathrm{LaB}_{6}$ nanostructures is therefore of great interest. For FE applications, wellaligned vertical nanowires with a high density are especially desirable because such morphology can enhance the FE properties. To our knowledge, the controllable synthesis and tuning of FE properties of $1 \mathrm{D} \mathrm{LaB}_{6}$ nanowires have not yet to be demonstrated.

In addition to the work function and morphology of the cathode materials, the ambient temperature of the cathode is an important factor for FE performance, which has a strong influence on the material FE characteristics. For example, temperature-dependent field-electron emission ${ }^{17-20}$ can provide deep insight into the physical properties of a nanostructure, reveal the relationship between the electron emission characteristics and different temperature conditions, and allow the investigator to understand the direct thermal electric conversion. Recently, extensive efforts have been devoted to a study of temperature-dependent FE of CNTs, ${ }^{20,21}$ $\mathrm{ZnO}$ nanowires, ${ }^{17}$ AlN nanotips, ${ }^{5}$ graphene films ${ }^{19}$ and $\mathrm{SiC}$ nanostructures. ${ }^{18}$ All of the authors obtained similar results: both the turn-on and threshold electric fields decreased with increasing temperature. However, an elaborate research program on high- temperature $\mathrm{FE}$ for aligned $\mathrm{LaB}_{6}$ nanowire arrays has not yet been initiated, making the investigation of temperature-dependent fieldemitter $\mathrm{LaB}_{6}$ arrays indispensable.

In this work, we have developed an effective, easily controlled, one-step, catalyst-free CVD method to synthesize high-quality, uniform $\mathrm{LaB}_{6} 1 \mathrm{D}$ nanostructures with different morphologies such as sparse and nanoneedles, dense nanorods and well-aligned nanowire arrays. The morphology of $\mathrm{LaB}_{6}$ nanostructures can be adjusted by changing the reaction temperature and the distance between the precursors and the substrate. Our results demonstrate that among the above-mentioned four nanostructures, the well-aligned nanowire arrays are the best field emitters, with a low turn-on field

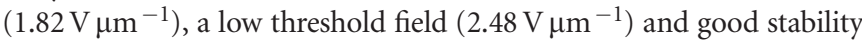
(testing time, $1000 \mathrm{~min}$; fluctuation $<6.0 \%$ ). The temperature-dependent FE properties of the aligned $\mathrm{LaB}_{6}$ nanowire arrays were also investigated to elucidate the FE mechanism of the arrays.

\section{EXPERIMENTAL PROCEDURES}

Synthesis of $\mathrm{LaB}_{6}$ nanostructures was conducted in a horizontal tube furnace with an internally mounted 50 -mm outer-diameter quartz tube (as shown in Supplementary Figure S1). In brief, $0.2 \mathrm{~g}$ of lanthanum chloride heptahydrate $\left(\mathrm{LaCl}_{3} \cdot 7 \mathrm{H}_{2} \mathrm{O}\right.$; mass purity, 99.9\%) was loaded near the closed end of the quartz test tube and deposited in the uniform temperature region, while $\mathrm{Si}$ wafers were placed upstream to act as deposition substrates. The distance between the substrate and the source was $\sim 3 \mathrm{~cm}$ for sample a, $\sim 5 \mathrm{~cm}$ for sample $\mathbf{c}$, and $\sim 8 \mathrm{~cm}$ for samples $\mathbf{b}$ and $\mathbf{d}$. Before heating, each quartz tube was evacuated and washed with a mixed gas $\left(30 \% \mathrm{H}_{2}+70 \% \mathrm{Ar}\right.$, volume percent calculation). The quartz tube was then heated to $930{ }^{\circ} \mathrm{C}$ (samples a and b) or $970{ }^{\circ} \mathrm{C}$ ( samples $\mathbf{c}$ and $\mathbf{d}$ ) at a heating rate of $\sim 15^{\circ} \mathrm{C} \mathrm{min}^{-1}$ under a base pressure of $\sim 5 \mathrm{~Pa}$. Then, a steady mixed gas ( $5 \%$ volume $\mathrm{B}_{2} \mathrm{H}_{6}+95 \%$ volume $\mathrm{Ar})$ at $\sim 30$ s.c.c.m. was flowed for $30 \mathrm{~min}$ under a reaction pressure of $\sim 15 \mathrm{~Pa}$. After the reaction, the furnace was cooled to RT under vacuum. Four representative samples (a, b, $\mathbf{c}$ and $\mathbf{d}$ ) were fabricated by varying experimental parameters; the detailed growth conditions are listed in Table 1.

The synthesized products were characterized by scanning electron microscopy (SEM; S-4800, Hitachi, Tokyo, Japan), X-ray diffraction (D8/advance, Bruker, Karlsruhe, Germany), Raman spectrometry (Horiba Jobin-Yoon T6400 instrument, Tokyo, Japan), transmission electron microscopy (TEM; JEM3000F instrument, JEOL, Tokyo, Japan) and X-ray energy dispersive spectrometry. X-ray photoelectron spectra were measured using an ESClab-220i-XL electron spectrometer (VG Scientific, UK) with $300 \mathrm{~W} \mathrm{Al} \mathrm{K \alpha}$ radiation. The FE properties were analyzed on a home-built parallel-plate electrode high-vacuum FE system with a base pressure of $\sim 5.0 \times 10^{-7} \mathrm{~Pa}$ at different controlled temperatures. The distance between the substrate surfaces and the anode of the vacuum chamber was fixed at $500 \mu \mathrm{m}$.

\section{RESULTS AND DISCUSSION}

The morphology, structure and growth mechanism of $\mathrm{LaB}_{6}$ nanostructures

Representative morphologies of $\mathrm{LaB}_{6}$ nanostructures obtained were investigated by FE SEM, as shown in Figure 1. The low-magnification

Table 1 Growth conditions for one-dimensional $\mathrm{LaB}_{6}$ nanostructures

\begin{tabular}{|c|c|c|c|c|c|c|c|c|}
\hline Sample & Si substrates & Catalysts & $\begin{array}{l}\text { Distance between } \\
\text { the source and } \\
\text { the substrates }(\mathrm{cm})\end{array}$ & $T(C)$ & $t(\min )$ & Reactionpressure $(\mathrm{Pa})$ & $\begin{array}{c}\text { Wash gas: the ratio } \\
\text { of } \mathrm{H}_{2} / \mathrm{Ar} \text { and } \\
\text { flow (s.c.c.m.) }\end{array}$ & $\begin{array}{l}\text { Reaction gas: the } \\
\text { ratio of } \mathrm{H}_{2} / \mathrm{B}_{2} \mathrm{H}_{6} \\
\text { and flow (s.c.c.m.) }\end{array}$ \\
\hline a & $<100>$ & No & 3 & 930 & 30 & $\sim 15$ & $3: 7 ; 100$ & $1: 19 ; 30$ \\
\hline b & $<100>$ & No & 8 & 930 & 30 & $\sim 15$ & $3: 7 ; 100$ & $1: 19 ; 30$ \\
\hline c & $<100>$ & No & 5 & 970 & 30 & $\sim 15$ & $3: 7 ; 100$ & $1: 19 ; 30$ \\
\hline d & $<100>$ & No & 8 & 970 & 30 & $\sim 15$ & $3: 7 ; 100$ & $1: 19 ; 30$ \\
\hline
\end{tabular}



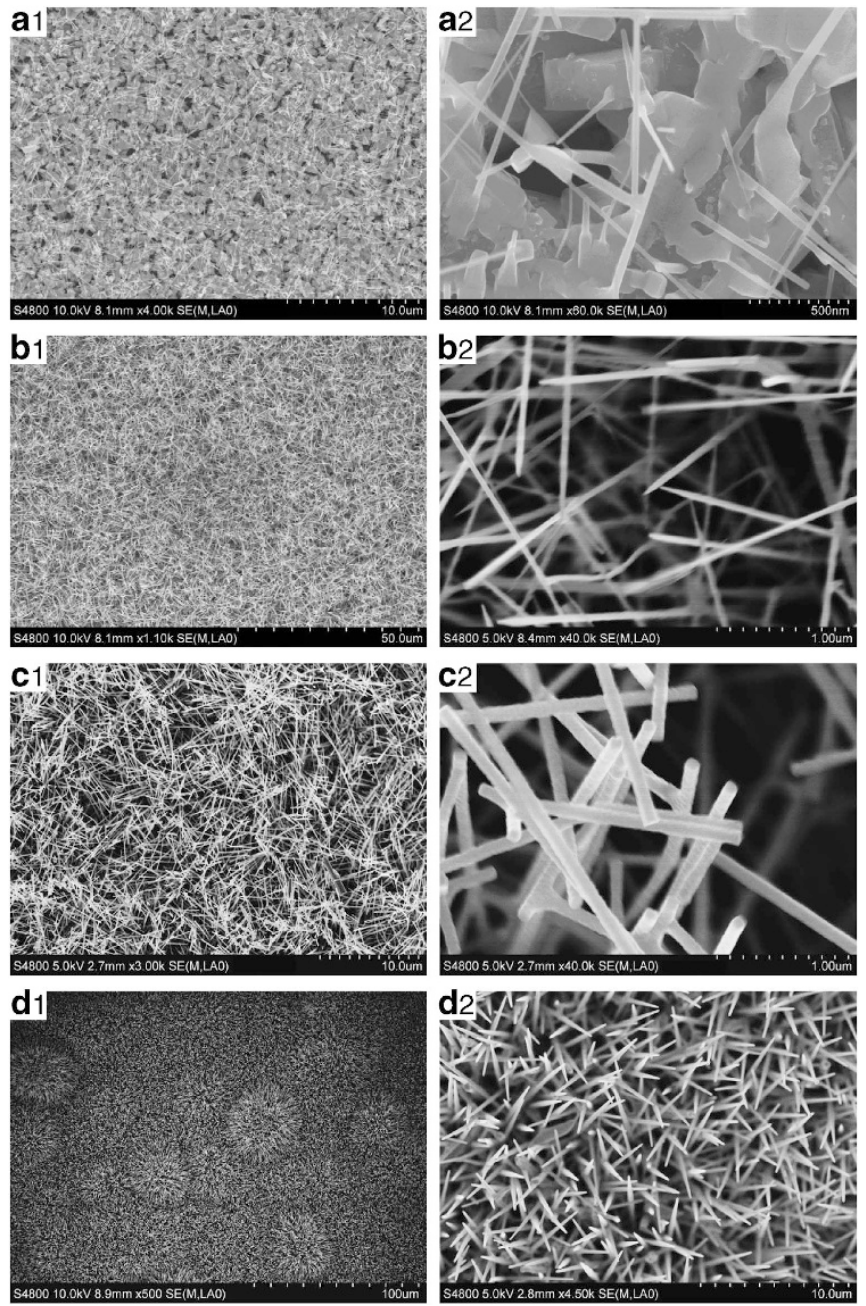

Figure 1 Typical scanning electron microscopy (SEM) image of several lanthanum hexaboride $\left(\mathrm{LaB}_{6}\right)$ nanostructures: $(\mathrm{a} 1, \mathrm{a} 2)$ sparse nanoneedles; (b1, b2) dense nanoneedles; (c1, c2) dense nanonrods; and (d1, d2) nanowire arrays.

SEM images (Figures 1a1, b1, c1 and d1) show that the nanostructures cover the entire substrates uniformly. The high-magnification SEM images (Figures 1a2, b2, c2 and d2) illustrate that the morphologies are quite different when different distances between the precursors and the substrates are utilized. At a short distance $(\sim 3 \mathrm{~cm})$ and low temperature $\left(930^{\circ} \mathrm{C}\right)$, sparse and thinner needle-like nanorods, with diameters of $\sim 30-50 \mathrm{~nm}$ and lengths up to several micrometers, are formed (Figure 1a). With an increase in the distance, longer and thicker needle-like nanowires grow (Figure 1b). The diameters of the nanowires are $\sim 70-130 \mathrm{~nm}$, and the lengths are $\sim 5-10 \mu \mathrm{m}$. The use of a higher-source temperature $\left(970{ }^{\circ} \mathrm{C}\right)$ and a short distance $(\sim 5 \mathrm{~cm})$ leads to the formation of dense nanorods. A dense carpet of nanorods, with a typical length up to $3-8 \mu \mathrm{m}$, covers the substrate (Figure $1 \mathrm{cl}$ ). High-magnification SEM images (Figure 1c2) show that the nanorods have a relatively uniform cross-section and a diameter of $100 \mathrm{~nm}$. When the distance increases to $\sim 8 \mathrm{~cm}$ at a higher temperature $\left(970{ }^{\circ} \mathrm{C}\right)$, high-quantity, smooth, well-faced $\mathrm{LaB}_{6}$ nanowire arrays grow nearly vertically on the substrates (Figure $1 \mathrm{~d} 1$ and Supplementary Figure S2). A magnified view of the nanowire arrays, taken from the top (Figure $1 \mathrm{~d} 2$ ), reveals that the $\mathrm{LaB}_{6}$ structures have a smooth and masonry tower-like morphology, with a typical diameter of $\sim 80-120 \mathrm{~nm}$ and a length of $\sim 15-20 \mu \mathrm{m}$.

The detailed microstructures of the well-aligned $\mathrm{LaB}_{6}$ nanowires arrays were further studied by TEM. Figure $2 \mathrm{a}$ shows a typical low-magnification TEM image of a nanowire portion with a diameter of $\sim 90 \mathrm{~nm}$. Figure $2 \mathrm{~b}$ gives a high-resolution TEM lattice image, demonstrating the single crystalline nature of the nanowires. Two groups of mutually perpendicular interference fringes can be seen clearly, and the two d-spacings, which are $\sim 0.41 \mathrm{~nm}$ each, correspond to the (100) and (010) crystal faces. Selected area electron diffraction was used on tens of nanowires to determine their structures. Figure $2 \mathrm{c}$ shows a typical selected area electron diffraction pattern taken along the (001) crystal zone axis. Selected area electron diffraction reveals that $\mathrm{LaB}_{6}$ nanowires adopted a single crystal structure, and the calculated lattice constant is $\mathrm{a}=0.41 \mathrm{~nm}$, which is close to the lattice constant of cubic $\mathrm{LaB}_{6}$, according to the JCPDS database (No. 73-1669, $\mathrm{a}=0.416 \mathrm{~nm}$ ). Figure $2 \mathrm{f}$ illuminates the corresponding structural model. The superb crystal quality excludes the possibility of any grain boundaries and/or other interfaces, which usually act as recombination sites in polycrystalline materials. This crystal quality should favor improved FE and electron transport properties. The La and $\mathrm{B}$ elemental maps from $\mathrm{LaB}_{6}$ nanowire arrays are displayed in Figures $2 \mathrm{~d}$ and e. Figure $2 \mathrm{~d}$ reveals the uniform distribution of $\mathrm{La}$ in the nanowires. Compared with the La species, it is difficult to detect the $\mathrm{B}$ species accurately (Figure 2e) because of the small atom number. The results of the TEM, high-resolution TEM, electron diffraction analysis and elemental mapping confirm the presence of high-quality single-crystalline $\mathrm{LaB}_{6}$ nanowires oriented along the [100] direction.

An X-ray diffraction pattern of the aligned $\mathrm{LaB}_{6}$ nanowire arrays is presented in Figure 3a. Except for the peaks of Si from the substrate (JCPDS Card, No. 78-2500), the rest of the peaks can readily be indexed to cubic $\mathrm{LaB}_{6}$ with a lattice parameter of $\mathrm{a}=0.419 \mathrm{~nm}$, matching the literature data (JCPDS Card, No. 73-1669) well. The sharp diffraction peaks indicate the good crystallinity of the product. The relative intensities of the peaks differ from the standard pattern of a bulk material because of the preferred orientation and distribution of $\mathrm{LaB}_{6}$ nanowires. A pattern taken from the nanowires shows a strong (100) diffraction peak, possibly owing to the growth of cubic $\mathrm{LaB}_{6}$ along the [100] direction, in accord with the high-resolution TEM results. Raman spectroscopy was employed to investigate the nanostructures further. Figure $3 \mathrm{~b}$ depicts a room-temperature microRaman spectrum of $\mathrm{LaB}_{6}$ nanowire arrays. The Pm-3m symmetry of the $\mathrm{LaB}_{6}$ structure gives us the following normal lattice vibration modes: $\Gamma=\mathrm{A}_{1 \mathrm{~g}}+\mathrm{E}_{\mathrm{g}}+\mathrm{T}_{1 \mathrm{~g}}+\mathrm{T}_{2 \mathrm{~g}}+2 \mathrm{~T}_{1 \mathrm{u}}+\mathrm{T}_{2 \mathrm{u}}$, where the Ramanactive phonons are $A_{1 g}, E_{g}$ and $T_{2 g}$; two $T_{1 u}$ modes are infrared active; and $\mathrm{T}_{1 \mathrm{~g}}$ and $\mathrm{T}_{2 \mathrm{u}}$ are optically inactive. The peaks at 761,1121 and $1260 \mathrm{~cm}^{-1}$ match the Raman-active modes $\mathrm{T}_{2 \mathrm{~g}}, \mathrm{E}_{\mathrm{g}}$ and $\mathrm{A}_{1 \mathrm{~g}}$ of $\mathrm{LaB}_{6}$, respectively, and they completely satisfy the polarization selection rule in the cubic symmetry. An extra peak located at $213 \mathrm{~cm}^{-1}$ can be regarded as the vibration of the rare earth ions in the cage and can be assigned as the 'optical' $\mathrm{T}_{1 \mathrm{u}}$ mode. ${ }^{22}$ The mode $<200 \mathrm{~cm}^{-1}$ and a broad peak at $1400 \mathrm{~cm}^{-1}$, denoted by asterisks, are commonly observed for trivalent and intermediate-valent crystals. ${ }^{20}$ The band around $1156 \mathrm{~cm}^{-1}$, denoted by arrows, is characteristic of the $\mathrm{LaB}_{6}$ sample, as reported in the literature. ${ }^{23}$ The relatively intense and sharp peaks suggest that the nanowires are highly crystalline, consistent with the X-ray diffraction pattern and the high-resolution TEM results.

Further evidence of the high quality of the crystal was obtained using X-ray photoelectron spectroscopy. Figure 4a shows the survey 

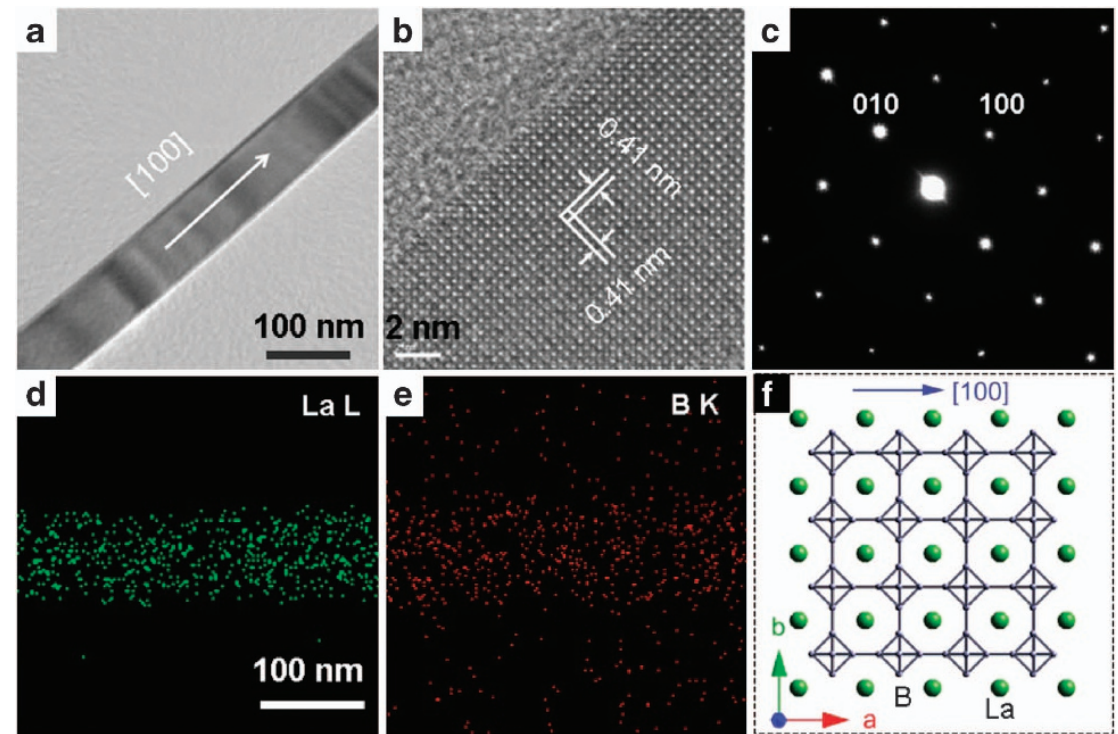

Figure 2 Transmission electron microscopy (TEM) images of lanthanum hexaboride $\left(\right.$ LaB $\left._{6}\right)$ nanowires: (a) TEM image; (b) high-resolution TEM (HRTEM) image; (c) the corresponding selected area electron diffraction (SAED) pattern; (d) La elemental maps; (e) B elemental maps; (f) atomic model of a cubic $\mathrm{LaB}_{6}$ with the [100] growth direction.

spectrum of the aligned $\mathrm{LaB}_{6}$ nanowire arrays, and no peaks of other elements except $\mathrm{La}, \mathrm{B}, \mathrm{O}$ and $\mathrm{C}$ are seen. The $\mathrm{La}$ and $\mathrm{B}$ signals come mainly from the synthesized sample, and the $\mathrm{C}$ and $\mathrm{O}$ peaks derive from atmospheric contamination owing to the exposure to air. The La $3 \mathrm{~d}$ peaks at 838.9 ( $\mathrm{La} 3 \mathrm{~d} 5) \mathrm{eV}$ and 853.0 ( $\mathrm{La} 3 \mathrm{~d} 3) \mathrm{eV}$, shown in Figure $4 \mathrm{~b}$, and the B 1 s peak at $188.0 \mathrm{eV}$, shown in Figure $4 \mathrm{c}$, agree well with the data obtained in earlier reports ${ }^{24}$ and serve as additional confirmation of the $\mathrm{LaB}_{6}$ phase.

In most cases, the mechanism of formation of nanostructures has been suggested to be vapor-liquid-solid growth ${ }^{25}$ and the vapor-solid mechanism. ${ }^{26}$ In our experiments, none of the $\mathrm{LaB}_{6}$ nanostructures have condensed melts at the tip parts, as shown in Figures 1 and 2, which excludes the vapor-liquid-solid mechanism, and self-catalysis should be considered. ${ }^{12}$ To give a conceptual description of $\mathrm{LaB}_{6}$ nanostructures, we propose the model sketched in Supplementary Figure S3. Initially, at a high temperature, the $\mathrm{La}$ atoms from the $\mathrm{LaCl}_{3}$ precursors in vacuum were evaporated onto the Si substrates and formed La nanodroplets (Supplementary Figure S3a). When $\mathrm{H}_{2} \mathrm{~B}_{6}$ was introduced, the $\mathrm{B}$ atoms from the boron precursor were absorbed by the nanodroplets, resulting in the formation of some $\mathrm{LaB}_{6}$ nanoclusters, which, in turn, served as nuclei for nanowire growth (Supplementary Figure S3b). Subsequently, the growth of $\mathrm{LaB}_{6}$ nanowires began and continued as long as appropriate quantities of $\mathrm{La}$ and $\mathrm{B}$ atoms were available (Supplementary Figure S3c). Finally, when heating was stopped, the growth terminated and the $\mathrm{LaB}_{6}$ nanowire was formed (Supplementary Figure S3d). For the well-aligned $\mathrm{LaB}_{6}$ nanowire arrays, it is possible that during the third stage of growth (Supplementary Figure S3c), the parallel (or nearly parallel) growth might be terminated due to collisions between the individual wires. Finally, the long nanowires grew along the normal or nearly normal direction to the substrate (Supplementary Figure S3d). A similar mode was also observed in the growth of Mo nanowire arrays. ${ }^{27}$ To illustrate the proposed mechanism, the samples were studied after different reaction times of 5, 10, 15 and $30 \mathrm{~min}$ (shown in Supplementary Figure S4). Although Supplementary Figure S4 does not provide in situ or in-time illustration, the results agree relatively well with the overall sketch. The growth of the aligned $\mathrm{LaB}_{6}$ nanowire arrays was therefore attributed to the vapor-solid mechanism.

\section{FE properties of $\mathrm{LaB}_{6}$ nanostructures}

FE measurements of the synthesized products were conducted in a vacuum chamber at a pressure of $5.0 \times 10^{-7} \mathrm{~Pa}$ at RT. Figure 5 depicts the emission current density versus the applied field curve $(J-E)$ at an anode-sample distance of $500 \mu \mathrm{m}$ (that is, from $\mathrm{LaB}_{6}$ nanostructures to the anode). We define the turn-on field $\left(E_{\mathrm{to}}\right)$ and the threshold field $\left(E_{\mathrm{thr}}\right)$ as the electric fields required to produce a current density of $10 \mu \mathrm{A} \mathrm{cm}^{-2}$ and $1 \mathrm{~mA} \mathrm{~cm}^{-2}$, respectively. The wellaligned $\mathrm{LaB}_{6}$ nanowire arrays (sample $\mathbf{d}$ ) exhibited the best $\mathrm{FE}$

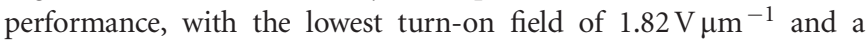

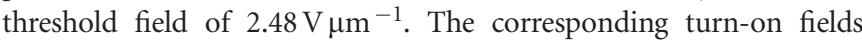
were $4.12,2.16$ and $2.80 \mathrm{~V} \mathrm{\mu m}^{-1}$ for the other samples denoted as $\mathbf{a}, \mathbf{b}$ and c, respectively, as shown in Table 2 . The data (as summarized in Table 3 ) suggest that the $E_{\text {to }}$ and $E_{\text {thr }}$ of aligned $\mathrm{LaB}_{6}$ nanowire arrays are smaller than the $E_{\mathrm{to}}$ and $E_{\mathrm{thr}}$ of most nanostructure-based field emitters. Normally, the current density $(J)$ produced by a given electric field $(E)$ is described by the F-N equation: ${ }^{9}$

$$
J=A_{\mathrm{E}} \frac{\beta^{2} E^{2}}{\phi} \exp \left(\frac{-B_{\mathrm{E}} \phi^{3 / 2}}{\beta E}\right)
$$

or

$$
\ln \left(J / E^{2}\right)=\ln \left(A \frac{\beta^{2}}{\phi}\right)-\frac{B_{\mathrm{E}} \phi^{3 / 2}}{\beta E}
$$

where $A_{\mathrm{E}}=1.54 \times 10^{-6} \mathrm{AeVV}^{-2}, B_{\mathrm{E}}=6.83 \times 10^{3} \mathrm{eV}^{-3 / 2} \mu \mathrm{m}^{-1}, J$ is the current density, $\beta$ is the field enhancement factor, $E$ is the applied field and $\varphi$ is the work function of the emitting material $(2.6 \mathrm{eV}$ for $\left.\mathrm{LaB}_{6}\right)$. The inset in Figure 5 shows the F-N plots (that is, $\ln \left(J / E^{2}\right)$ vs $1 / E$; the F-N plots), and these plots have an approximately linear relationship within the measurement range, confirming that the electron emission from $\mathrm{LaB}_{6}$ nanostructures follows the traditional 

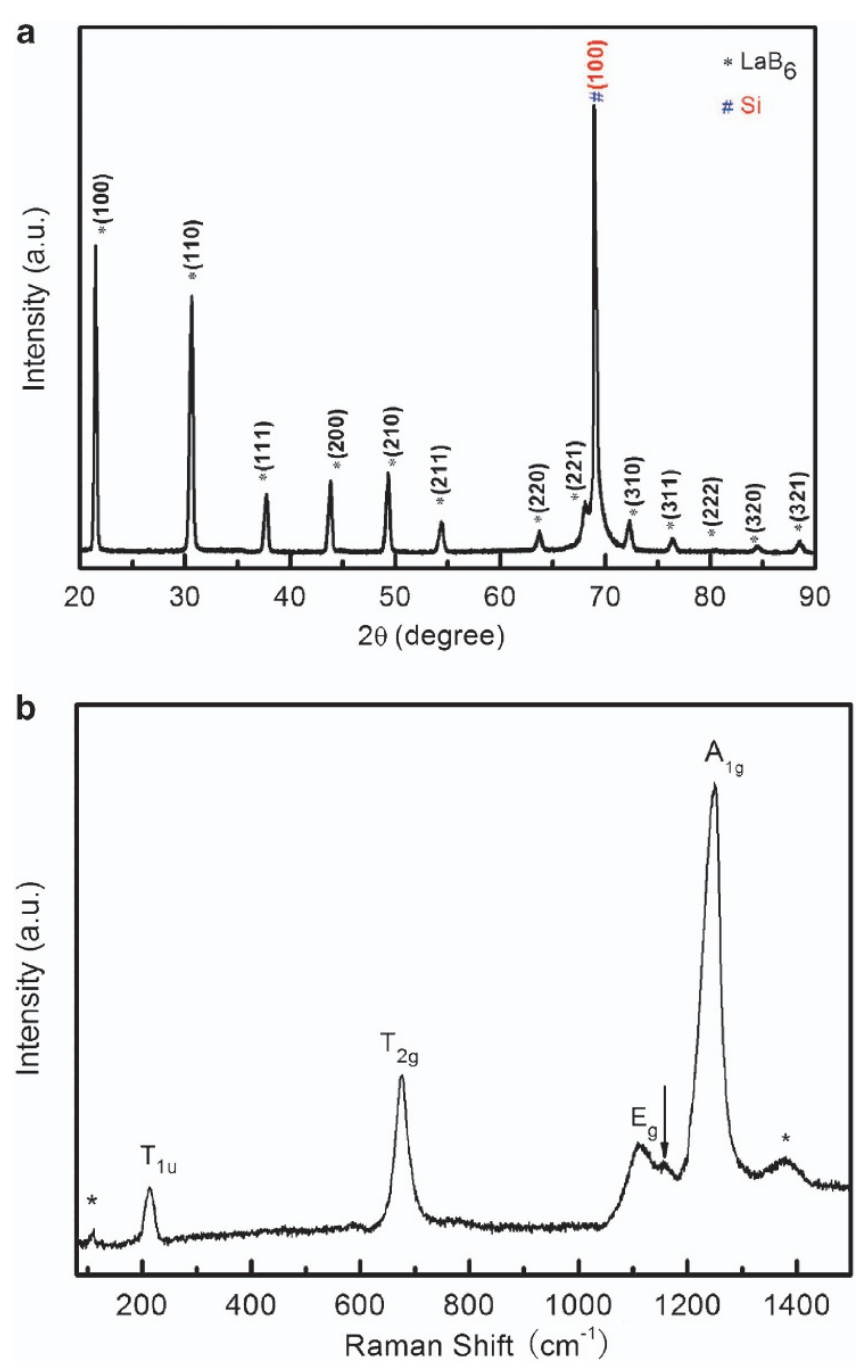

Figure 3 (a) X-ray diffraction (XRD) pattern of $\mathrm{LaB}_{6}$ nanostructures; (b) micro-Raman spectrum of lanthanum hexaboride $\left(\mathrm{LaB}_{6}\right)$ nanostructures at room temperature (RT).

F-N behavior. The calculated field-enhancement factors are also summarized in Table 2. The dense nanoneedles have the highest $\beta$-value (1441) compared with the sparse nanoneedles (463), the dense nanorods (884) and the well-aligned $\mathrm{LaB}_{6}$ nanowire arrays (1072). Although $\beta$-values are related to the emitter geometry (the aspect ratio), sample a (sparse nanoneedles) exhibited a lower field-enhancement factor, possibly owing to fewer emitters (compared with samples $\mathbf{b}, \mathbf{c}$ and $\mathbf{d}$ ). Furthermore, these $\beta$-values are comparable to the values summarized in Table 3 and are more than sufficient for device applications.

The stability of the field emitters is another technologically important parameter. Figure 6 shows the variation of the emission current density of sample $\mathbf{d}$ (the aligned $\mathrm{LaB}_{6}$ nanowire arrays) over a period of $\sim 1000 \mathrm{~min}$ in a macroscopic electric field of $2.30 \mathrm{~V} \mu \mathrm{m}^{-1}$. A small current fluctuation $<6 \%$ was observed, which is much more stable than previous reports, as summarized in Table 3. This fluctuation $(<6 \%)$ may be attributed to incompletely removed surface contamination because recently, Zhang et al..$^{39}$ reported that no current degradation occurs for $\mathrm{LaB}_{6}$ emitters after careful elimination of surface contamination by the field evaporation
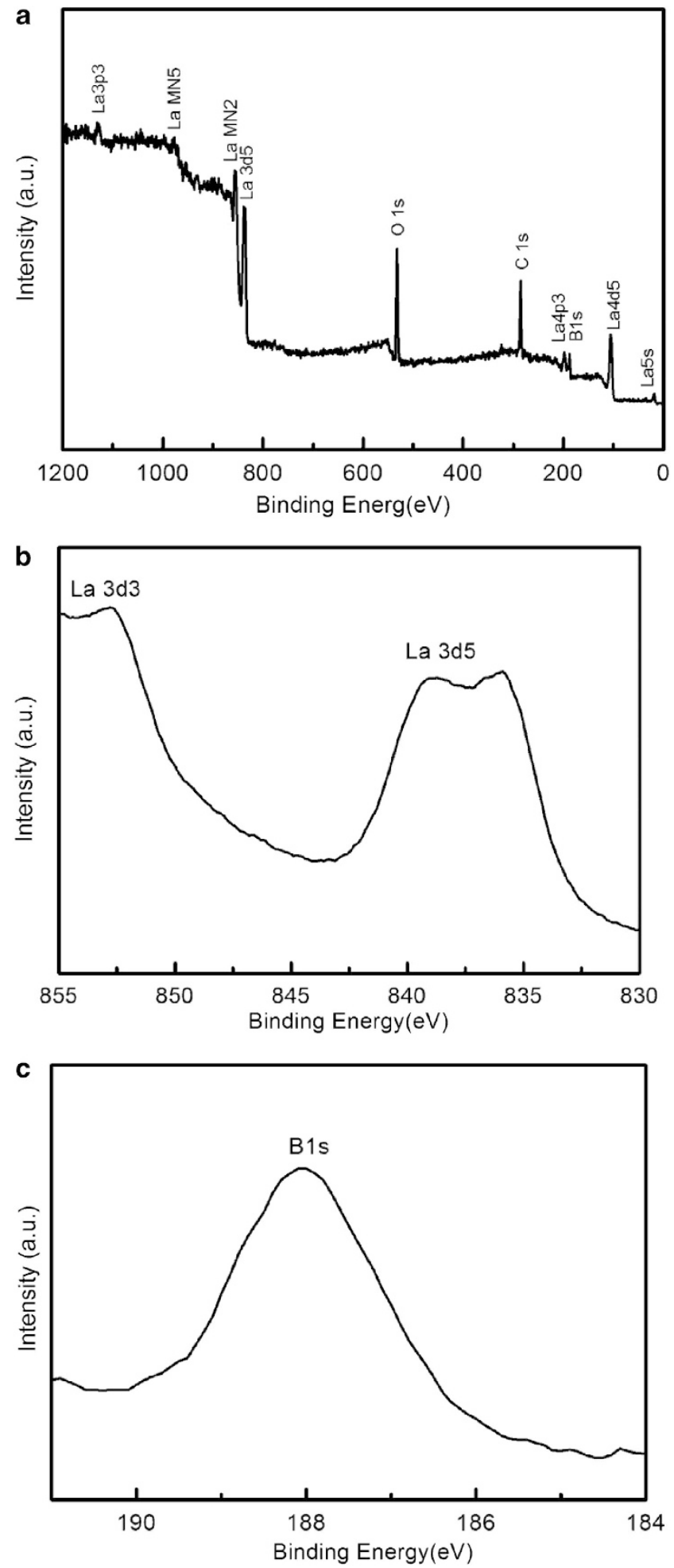

Figure 4 X-ray photoelectron spectroscopy (XPS) analysis of as-prepared lanthanum hexaboride $\left(\mathrm{LaB}_{6}\right)$ nanowire arrays: (a) survey spectrum; (b) La-3d-binding energy spectrum; (c) B-1s-binding energy spectrum.

treatment. If the surface of $\mathrm{LaB}_{6}$ nanostructures is entirely clean and contamination free, then the stability of the nanowire arrays may be even better than the value reported here. For comparison, Table 3 summarizes the key performance parameters of some field emitters 

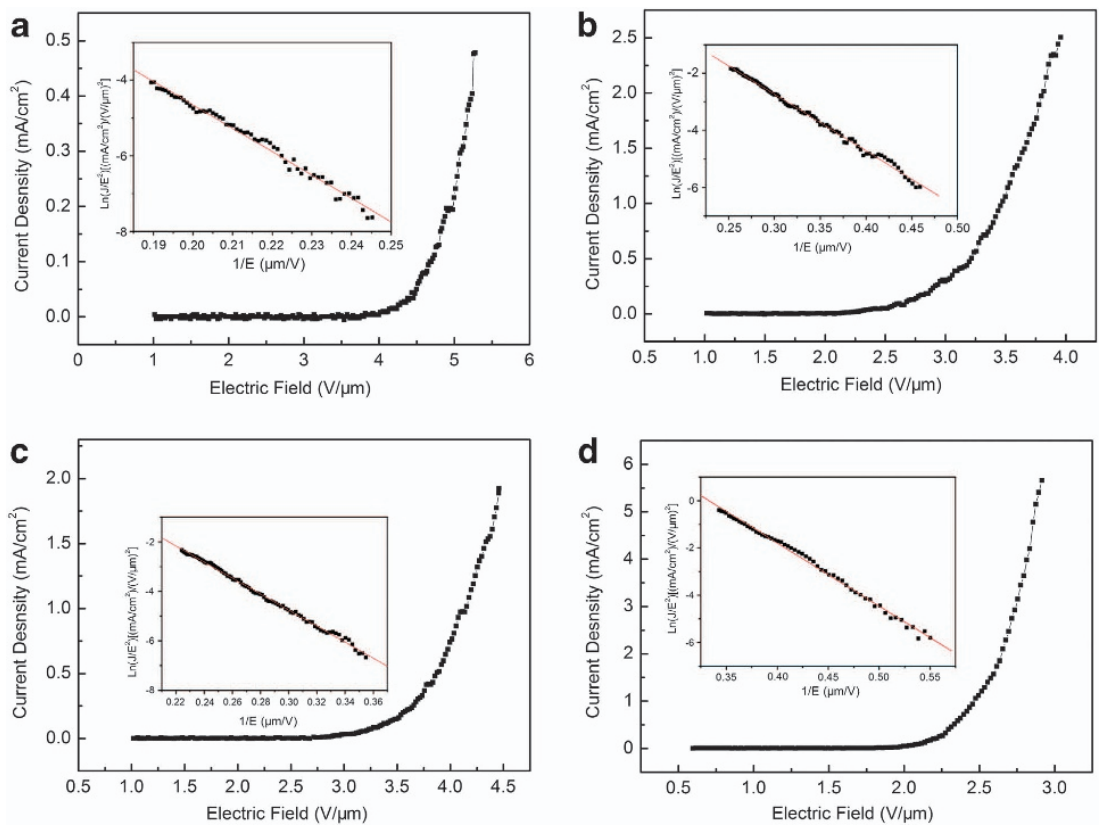

Figure 5 Field-emission (FE) properties of (a) sparse nanoneedles; (b) dense nanoneedles; (c) dense nanorods and (d) nanowire arrays. The insets are the corresponding Fowler-Nordheim $(F-N) \ln \left(J / E^{2}\right)-(1 / E)$ plots showing linear dependence.

Table 2 Turn-on fields, threshold fields and field-enhancement factors $(\beta)$ for the produced $\mathrm{LaB}_{6}$ nanostructures

\begin{tabular}{llccr}
\hline & & Turn-on field & Threshold field & \\
Sample & Morphology & $\left(V_{\left.\mu m^{-1}\right)}\right.$ & $\left(V \mu m^{-1}\right)$ & \multicolumn{1}{c}{$\beta$} \\
\hline a & Sparse nanoneedles & 4.12 & - & 463 \\
b & Dense nanoneedles & 2.16 & 3.48 & 1441 \\
c & Dense nanorods & 2.80 & 4.15 & 884 \\
d & Aligned nanowire arrays & 1.82 & 2.48 & 1072 \\
\hline
\end{tabular}

reported in the literature. The aligned $\mathrm{LaB}_{6}$ nanowire arrays are comparable to other nanostructured emitters. Such decent FE can be attributed to the specific characteristics (low work function, good electrical conductivity (metal), well-aligned vertical growth and high crystallinity) of our samples.

\section{Temperature-dependent FE properties of well-aligned $\mathrm{LaB}_{6}$ nanowire arrays}

For temperature-dependent FE, the total current density $J$ is given by the simplified F-N equation and the Richardson equation as follows: $:^{21,40}$

$$
\begin{aligned}
& J=J_{\mathrm{E}}+J_{\mathrm{T}}=A_{\mathrm{E}} \frac{\beta^{2} E^{2}}{\phi} \exp \left(\frac{-B_{\mathrm{E}} \phi^{3 / 2}}{\beta E}\right)\left[\frac{\theta}{\sin (\theta)}\right]+A_{\mathrm{R}} T^{2} e^{-\phi / k T} \\
& \theta \approx \frac{2.2 \pi(k T / q) \phi^{1 / 2}}{1.959 E}
\end{aligned}
$$

where $J_{\mathrm{E}}$ is the field current density, $J_{\mathrm{T}}$ is the thermionic current density, $A_{\mathrm{E}}=1.54 \times 10^{-6} \mathrm{~A} \mathrm{eV} \mathrm{V}^{-2}, B=6.83 \times 10^{3} \mathrm{eV}^{-3 / 2} \mu \mathrm{m}^{-1}, E$ is the applied field, $\beta$ is the field enhancement factor, $\varphi$ is the work function of the emitting material, $A_{\mathrm{R}}$ is the Richardson constant with a theoretical value of $120 \mathrm{Avm}^{-2} \mathrm{~K}^{-2}, T$ is the emitter temperature, $k$ is the Boltzmann constant and $\theta$ is the temperature correction factor.
Specific to $\mathrm{LaB}_{6}$ with a work function of $2.6 \mathrm{eV}$ and a temperature $<1000 \mathrm{~K}$, the value of $\left[\frac{\theta}{\sin (\theta)}\right]$ is always 1.0 within the temperature range that we studied. Therefore, the contribution of thermionic emission to the current density is much smaller than that of FE. The temperature-dependent $\mathrm{FE}$ characteristics can be expressed by the traditional F-N equations (1) and (2).

Figure 7 a depicts the $J-E$ plots of the well-aligned $\mathrm{LaB}_{6}$ nanowire arrays at an anode-sample distance of $500 \mu \mathrm{m}$ at different temperatures in the range of RT $(303 \mathrm{~K})-723 \mathrm{~K}$. All curves show the same characteristics: when the applied electric field is beyond a certain value, the current density increases nearly exponentially with an increase in the applied electric field. The turn-on field and threshold field decrease from 1.82 to 1.06 and 2.48 to $1.62 \mathrm{~V} \mathrm{\mu m}^{-1}$, respectively, (for $E_{\text {thr }}$ at $373 \mathrm{~K}$, refer to Supplementary Figure S5), as shown in Figure 7b. The FE is strongly dependent on the temperature. For example, the emission current density increases significantly from 0.20 to $9.05 \mathrm{~mA} \mathrm{~cm}^{-2}$ (at $2.20 \mathrm{~V} \mathrm{~m}^{-1}$, or $\sim 45$ times increase) upon increasing the temperature from RT to $723 \mathrm{~K}$, as also shown in Figure $7 \mathrm{~b}$. The decrease of the turn-on field and the increase of the emission current density with an increase of the temperature might be a result of the effective work function decrease for $\mathrm{LaB}_{6}$ nanowire arrays.

As demonstrated above, the temperature-dependent FE characteristics have the same nature as the FE at RT. To test whether the electron emission with the temperature originates from electron tunneling, the F-N equation is commonly used to examine this quantum effect. Figure $8 \mathrm{a}$ shows the F-N plots, $\ln \left(J / E^{2}\right)$ versus $1 / E$, under different temperatures. The approximately linear relationship of the F-N plots implies that the electron emission from $\mathrm{LaB}_{6}$ nanostructures in the range from RT to $723 \mathrm{~K}$ follows the conventional FE mechanism in which the electrons are tunneling through the potential barrier. Generally, the $\beta$-value is related to the emitter geometry (such as aspect ratios), the crystal structure and the spatial distribution of emitters. $\beta$ may thus be a constant in the range of temperatures tested (RT-723K). To estimate the effective work function $\left(\phi_{\mathrm{c}}\right)$ of the well-aligned $\mathrm{LaB}_{6}$ nanowire arrays, we assumed 
Table 3 Key field-emission performance parameters of some nanostructure field emitters reported in the literature and in this work

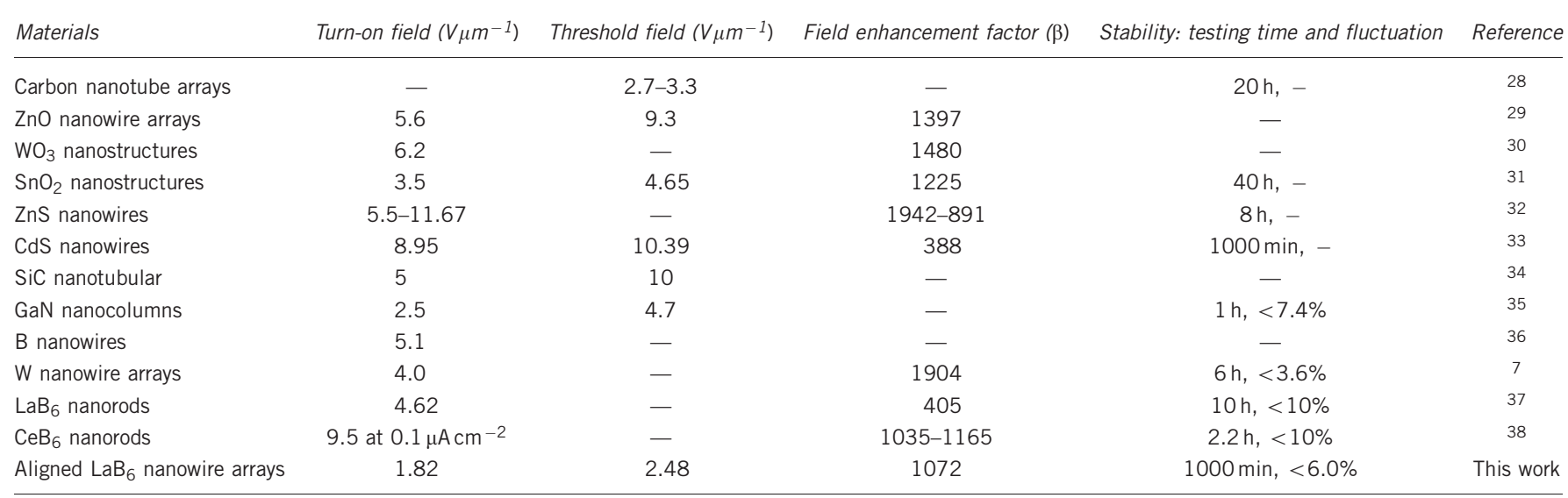

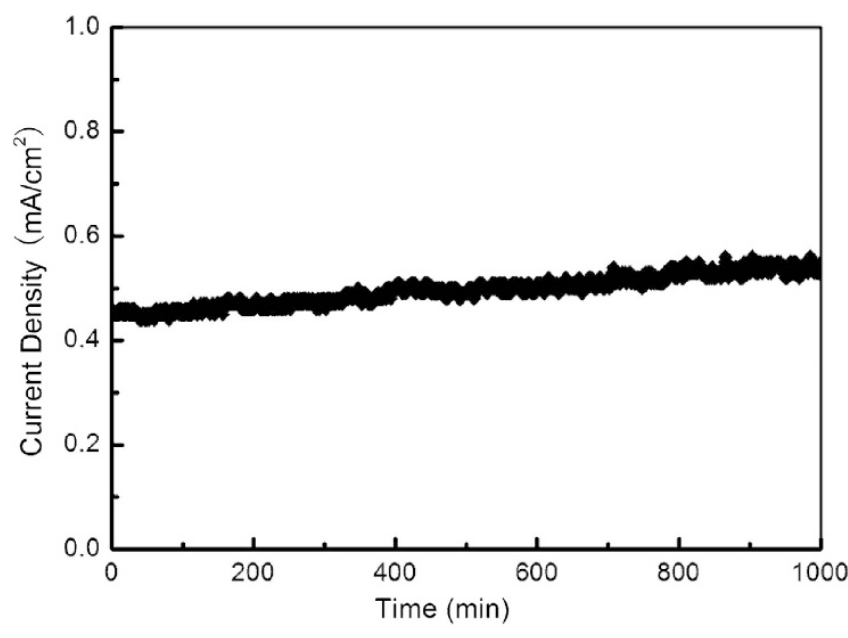

Figure 6 Representative stability curve of aligned lanthanum hexaboride $\left(\mathrm{LaB}_{6}\right)$ nanowire arrays at room temperature (RT).

that the initial work function at $\mathrm{RT}$ for $\mathrm{LaB}_{6}$ is $2.6 \mathrm{eV}$ and that $\beta$ does not change with temperature, and we calculated $\phi_{\mathrm{c}}$ through the relation $k=-B \varphi_{\mathrm{c}}{ }^{3 / 2} / \beta$ while making $\mathrm{F}-\mathrm{N}$ plots, as shown in Figure $8(\mathrm{~b})$. The effective work function $\left(\phi_{\mathrm{c}}\right)$ decreased with temperature, which explains the increase in emission current density within the measured temperature range.

To date, the temperature-dependent FE characteristics of nanostructures have not been completely understood. Kan et al. ${ }^{20}$ reported the enhanced thermal FE phenomenon of CNTs and ascribed these phenomena to defect band effects in the CNTs, which can raise the Fermi level into the band gap, and thus reduce the energy barrier through which the electrons must tunnel. Ahmed et al. ${ }^{21}$ also investigated the temperature-dependent $\mathrm{FE}$ properties of multiwalled CNTs and attributed the behavior to increasing enhancement factors. Choueib et al. ${ }^{41}$ reported the saturation effects in the emitter currents with temperature while observing the FE of individual single crystal $\mathrm{SiC}$ nanowires. $\mathrm{Li}$ et al. ${ }^{19}$ reported the temperature dependence of the FE characteristics of graphene film and attributed the temperature dependence to elevation of the Fermi level with temperature. Wei et al. ${ }^{18}$ observed the FE properties of $\mathrm{SiC}$ nanoneedles and ascribed them to the same phenomenon. Most authors attribute the enhanced FE properties to the increase of the
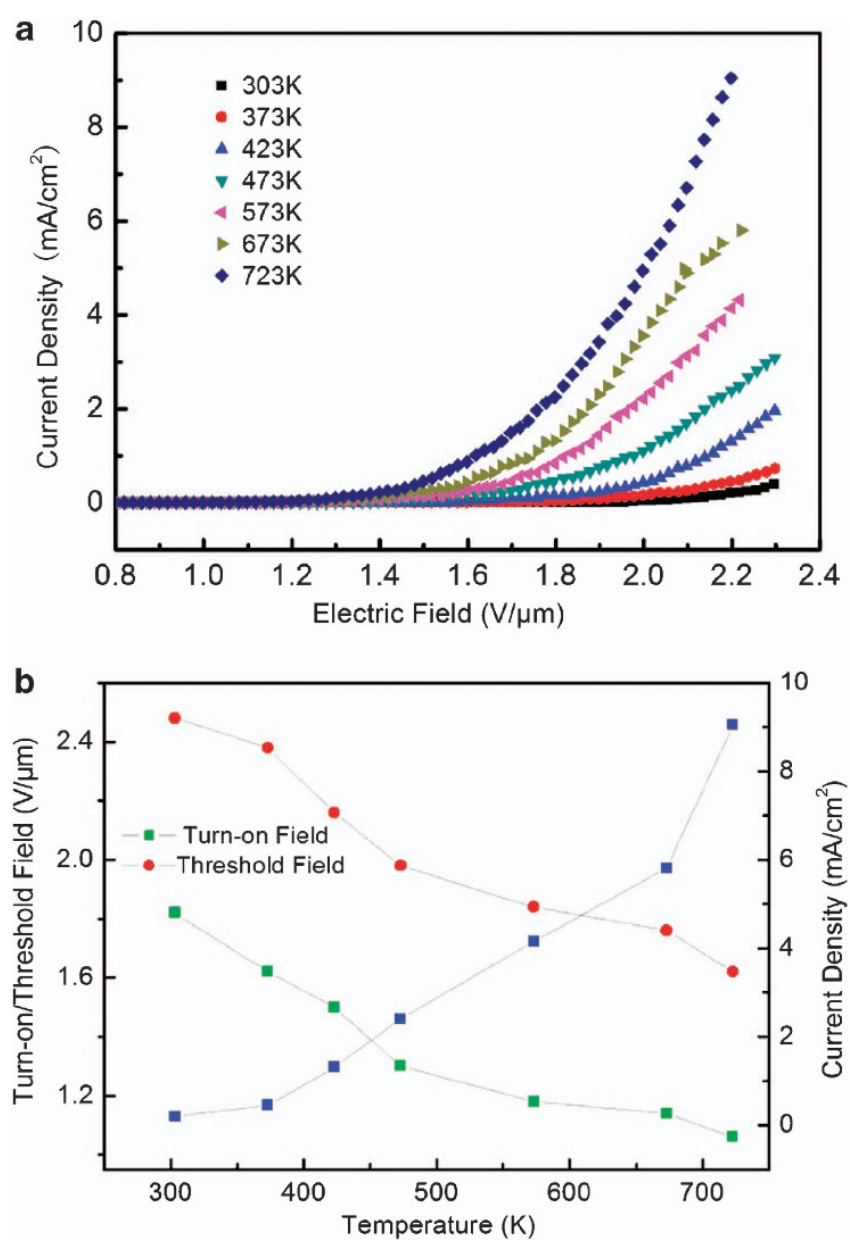

Figure 7 Dependence of field-emission (FE) current $J$ on the applied electric field $E$ of aligned lanthanum hexaboride $\left(\mathrm{LaB}_{6}\right)$ nanowire arrays at different temperatures: (a) emission current density versus the applied field curve $(J-E)$ plots; (b) variations of $E_{\mathrm{to}}, E_{\mathrm{thr}}$, and emission current at $2.20 \mathrm{Vm}^{-1}$.

Fermi level with temperature. $\mathrm{LaB}_{6}$ is a metal, and its Fermi level decreases slightly as temperature increases. The above model is therefore not suitable for $\mathrm{LaB}_{6}$ nanostructures. We noticed that a 

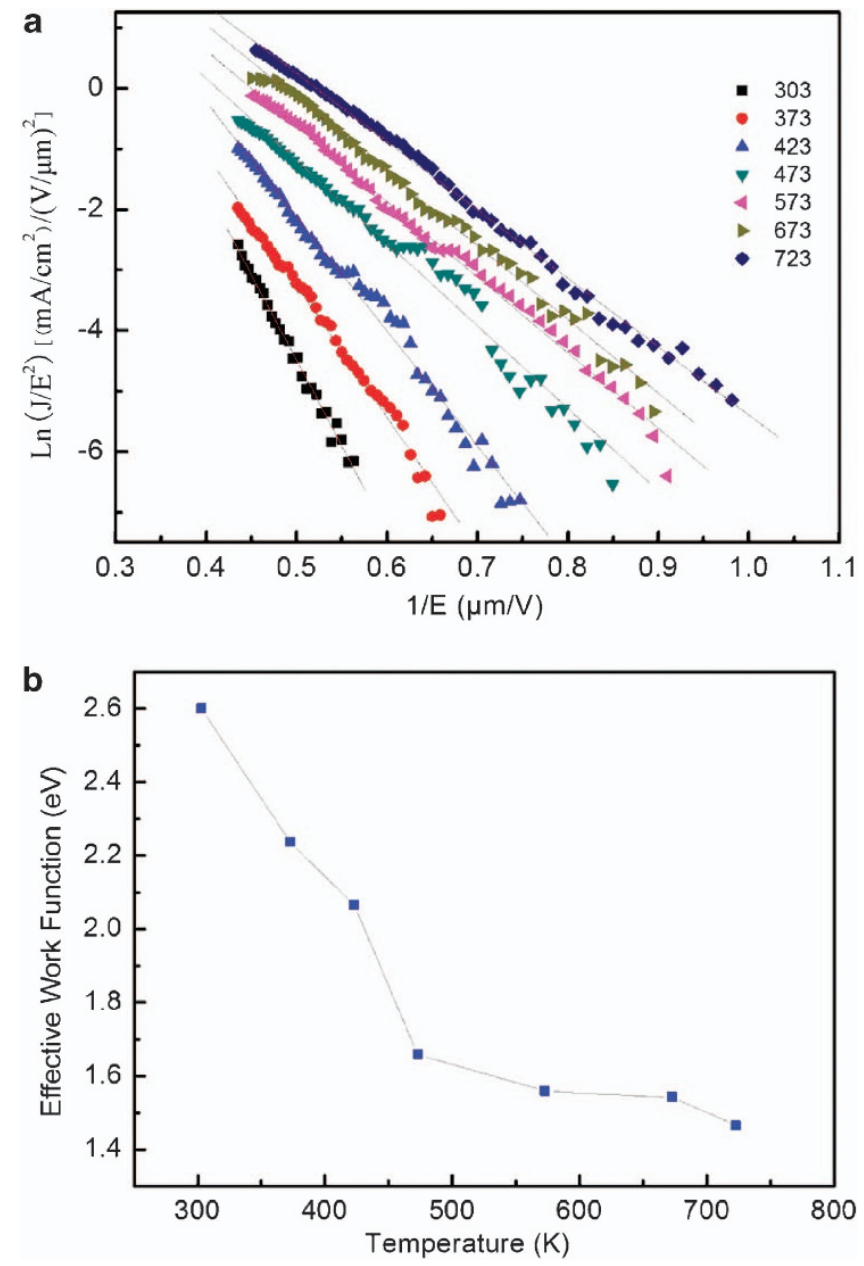

Figure 8 (a) The Fowler-Nordheim (F-N) plots for different temperatures (b) The dependence of the effective work function at ambient temperature.

higher vacuum is important to obtain reliable FE properties and an intrinsic FE mechanism. Before FE application, high temperature flashing ( $\sim 1773 \mathrm{~K}$, that is, $\left.1500{ }^{\circ} \mathrm{C}\right)$ is usually applied to eliminate surface contaminants to clean the $\mathrm{LaB}_{6}$ surface. In fact, Zhang et al. ${ }^{39}$ have demonstrated that the $\mathrm{FE}$ of a single $\mathrm{LaB}_{6}$ nanowire becomes stronger when the contaminant clusters on the nanowire tip are removed by the field evaporation treatment. On the basis of the above analysis, although the exact explanation of the observed temperature dependence of $\mathrm{LaB}_{6}$ emission requires further research, the following effects may be considered. The removal of surface-absorbed gas molecular contamination may be responsible for the increase in FE current. The effective work function $\phi_{\mathrm{c}}$ drops rapidly from RT to $473 \mathrm{~K}$ and is almost constant from 473 to $723 \mathrm{~K}$ (from Figure $8 \mathrm{~b}$ ). This behavior can be explained by the fact that most of the absorbed gas molecules (mainly nitrogen and oxygen because of sample exposure to air) were released quickly at a low temperature (from RT to $473 \mathrm{~K}$ ) and in high vacuum; the rest of the absorbed gas molecules were released slowly at a high temperature (from 473 to $723 \mathrm{~K}$ ). These gas molecules may have a negative effect on the emission current, which has been confirmed in $\mathrm{LaB}_{6}$ nanowires, ${ }^{39}$ $\mathrm{CNTs}^{42}$ and $\mathrm{ZnO}^{43}$ As the temperature increases, the adsorbed gas molecules release gradually, leading to a decrease in surface potential and the effective work function. Therefore, the effective work function of $\mathrm{LaB}_{6}$ nanostructures decreases with an increasing temperature.

\section{CONCLUSIONS}

In summary, we have developed a simple, effective, one-step, catalystfree CVD method for the synthesis of high-quality $\mathrm{LaB}_{6}$ nanostructures with different morphologies, such as sparse and dense nanoneedles, dense nanorods and nanowire arrays. FE measurements at RT showed that among all previously studied $1 \mathrm{D} \mathrm{LaB}_{6}$ nanostructures, the present nanowire arrays exhibit superior FE characteristics, with a low turn-on field of $1.82 \mathrm{~V} \mathrm{\mu m}^{-1}$, a low threshold field of $2.48 \mathrm{~V} \mathrm{\mu m}^{-1}$ and good stability. Temperature-dependent FE on the nanowire arrays showed that the turn-on and threshold electric fields decreased from 1.82 to 1.06 and from 2.48 to $1.62 \mathrm{~V} \mu \mathrm{m}^{-1}$, respectively, whereas the emission current density increased signifi-

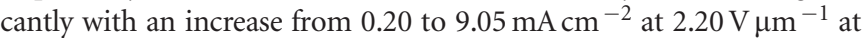
ambient temperatures from RT to $723 \mathrm{~K}$. The emission current of the aligned $\mathrm{LaB}_{6}$ nanowire arrays can be increased by $\sim 45$ times (to $9.05 \mathrm{~mA} \mathrm{~cm}^{-2}$ ) at $2.20 \mathrm{~V} \mathrm{\mu m}^{-1}$ when the temperature increases from RT to $723 \mathrm{~K}$. Such a good FE performance for the aligned $\mathrm{LaB}_{6}$ nanowire arrays suggests that they have potential for thermionic emission, field-induced emission and thermal field-induced emission applications, which are valuable for TEM, SEM and flat panel displays, as well as direct thermal-to-electrical power converters and other electronic devices that require high-performance electron sources.

\section{ACKNOWLEDGEMENTS}

This work was supported by the National 1000 Talents Program of China tanable in Huazhong University of Science and Technology (HUST), the National Nature Science Foundation of China (11004167), Program for Science \& Technology Innovation Talents in Universities of Henan Province (13HASTIT047), the Academic Excellent Young Teachers Program of Henan Province (2011GGJS-121) and the Excellent Young Teachers Program of Xinyang Normal University. The authors are indebted to Dr D L.Xu, Z.G Zhong and $\mathrm{J}$ Zhang for their technical assistance and kind help.

1 Kuznetzov, A. A., Lee, S. B., Zhang, M., Baughman, R. H. \& Zakhidov, A. A. Electron field emission from transparent multiwalled carbon nanotube sheets for inverted field emission displays. Carbon 48, 41-46 (2010).

2 Wang, X. D., Zhou, J., Lao, C. S., Song, J. H., Xu, N. S. \& Wang, Z. L. In situ field emission of density-controlled ZnO nanowire arrays. Adv. Mater. 19, 1627-1631 (2007)

3 Zhang, X. H., Gong, L., Liu, K., Cao, Y. Z., Xiao, X., Sun, W. M., Hu, X. J., Gao, Y. H., Chen, J., Zhou, J. \& Wang, Z. L. Tungsten oxide nanowires grown on carbon cloth as a flexible cold cathode. Adv. Mater. 22, 5292-5296 (2010).

4 Li, Z. J., Ren, W. P. \& Meng, A. L. Morphology-dependent field emission characteristics of SiC nanowires. Appl. Phys. Lett. 97, 263117 (2010).

5 Ji, X. H., Zhang, Q. Y., Lau, S. P., Jiang, H. X. \& Lin, J. Y. Temperature-dependent photoluminescence and electron field emission properties of AIN nanotip arrays. Appl. Phys. Lett. 94, 173106 (2009).

6 Nabi, G., Cao, C. B., Hussain, S., Khan, W. S., Sagar, R. R., Ali, Z., Butt, F. K., Usman, Z. \& Yu, D. P. Synthesis, photoluminescence and field emission properties of well aligned/well patterned conical shape GaN nanorods. Cryst. Eng. Comm. 14, 8492-8498 (2012).

7 Wang, S. L., He, Y. H., Fang, X. S., Zou, J., Wang, Y., Huang, H., Costa, P. M. F. J., Song, M., Huang, B. Y., Liu, C. T., Liaw, P. K., Bando, Y. \& Golberg, D. Structure and field-emission properties of sub-micrometer-sized tungsten-whisker arrays fabricated by vapor deposition. Adv. Mater. 21, 2387-2392 (2009).

8 Odom, T. W., Huang, J. L., Kim, P. \& Lieber, C. M. Atomic structure and electronic properties of single-walled carbon nanotubes. Nature 391, 62-64 (1998).

9 Fowler, R. H. \& Nordheim, L. W. Electron emission in intense electric fields. Proc. $R$. Soc. A 119, 173 (1928)

10 Zhang, H., Tang, J., Zhang, Q., Zhao, G. P., Yang, G., Zhang, J., Zhou, O. \& Qin, L. C. Field emission of electrons from single LaB6 nanowires. Adv. Mater. 18, 87-91 (2006).

11 Zhang, H., Zhang, Q., Tang, J. \& Qin, L. C. Single-crystalline LaB6 nanowires. J. Am. Chem. Soc. 127, 2862-2863 (2005) 
12 Zhang, H., Zhang, Q., Tang, J. \& Qin, L. C. Single-crystalline CeB6 nanowires. J. Am. Chem. Soc. 127, 8002-8003 (2005).

13 Zhang, H., Zhang, Q., Zhao, G. P., Tang, J., Zhou, O. \& Qin, L. C. Single-crystalline GdB6 nanowire field emitters. J. Am. Chem. Soc. 127, 13120-13121 (2005).

14 Xu, J. Q., Zhao, Y. M. \& Zou, C. Y. Self-catalyst growth of LaB6 nanowires and nanotubes. Chem. Phys. Lett. 423, 138-142 (2006).

15 Brewer, J. R., Deo, N., Wang, M. Y. \& Cheung, C. L. Lanthanum hexaboride nanoobelisks. Chem. Mater. 19, 6379-6381 (2007)

16 Peshev, P. A. A. Thermodynamic estimation of the chemical vapor deposition of some borides. J. Solid State Chem. 154, 157-161 (2000).

17 Liao, L., Zhang, W. F., Lu, H. B., Li, J. C., Wang, D. F., Liu, C. \& Fu, D. J. Investigation of the temperature dependence of the field emission of $\mathrm{ZnO}$ nanorods. Nanotechnology 18, 225703-225707 (2007)

18 Wei, G., Liu, H. Y., Shi, C. K., Gao, F. M., Zheng, J. J., Wei, G. D. \& Yang, W. Y. Temperature-dependent field emission properties of 3C-SiC nanoneedles. J. Phys. Chem. C 115, 13063-13068 (2011).

19 Li, J., Chen, J. T., Shen, B. S., Yan, X. B. \& Xue, Q. J. Temperature dependence of the field emission from the few-layer graphene film. Appl. Phys. Lett. 99, 163103-163105 (2011).

20 Kan, M. C., Huang, J. L., Sung, J. C., Chen, K. H. \& Yau, B. S. Thermionic emission of amorphous diamond and field emission of carbon nanotubes. Carbon 41, 2839-2845 (2003).

21 Ahmed, S. F., Das, S., Mitra, M. K. \& Chattopadhyay, K. K. Effect of temperature on the electron field emission from aligned carbon nanofibers and multiwalled carbon nanotubes. Appl. Sur. Sci. 254, 610-615 (2007).

22 Ogita, N., Nagai, S., dagawa, M. U., Iga, F., Sera, M., Oguchi, T., Akimitsu, J. \& Kunii, S. Raman scattering study of rare-earth hexaboride. Physica B. 359, 941-943 (2005).

23 Schmechel, R., Werheit, H. \& Paderno, Y. B. FT Raman spectroscopy of some metal hexaborides. J. Solid State Chem. 133, 264-268 (1997).

24 Selvan, R. K., Genish, I., Perelshtein, I., Moreno, J. M. C. \& Gedanken, A. Single step, low-temperature synthesis of submicron-sized rare earth hexaborides. J. Phys. Chem. C. 112, 1795-1802 (2008).

25 Xia, Y. N., Yang, P. D., Sun, Y. G., Wu, Y. Y., Mayer, B., Gates, B., Yin, Y. D., Kim, F. \& Yan, Y. Q. One-dimensional nanostructures: synthesis, characterization, and applications. Adv. Mater. 15, 353-389 (2003).

26 Pan, Z. W., Dai, Z. R. \& Wang, Z. L. Nanobelts of semiconducting oxides. Science 291, 1947-1949 (2001).

27 Zhou, J., Deng, S. Z , Gong, L., Ding, Y., Chen, J., Huang, J. X Chen, J., Xu, N. S. \& Wang, Z. L. Growth of large-area aligned molybdenum nanowires by high temperature chemical vapor deposition: synthesis, growth mechanism, and device application. J. Phys. Chem. B. 110, 10296-10302 (2006).

28 Fan, S. S., Chapline, M. G., Franklin, N. R., Tombler, T. W., Cassell, A. M. \& Dai, H. J. Self-oriented regular arrays of carbon nanotubes and their field emission properties. Science 283, 512-514 (1998).

29 Wang, Z. Q., Gong, J. F., Su, Y., Jiang, Y. W. \& Yang, S. G. Six-fold-symmetrical hierarchical $\mathrm{ZnO}$ nanostructure arrays: synthesis, characterization, and field emission properties. Cryst. Growth Des. 10, 2455-2459 (2010).

30 Liu, F., Mo, F. Y., Jin, S. Y., Li, L., Chen, Z. S., Sun, R., Chen, J., Deng, S. Z. \& Xu, N. S. A novel lift-off method for fabricating patterned and vertically-aligned W18049 nanowire arrays with good field emission performance. Nanoscale 3, 1850-1854 (2011).

31 Fang, X. S., Yuan, J., Hu, L. F., Liu, H. \& Lee, P. S. Thin SnO2 nanowires with uniform diameter as excellent field emitters: a stability of more than 2400 min. Adv. Funct. Mater. 22, 1613-1622 (2012).

32 Hafeez, M., Zhai, T. Y., Bhatti, A. S., Bando, Y. \& Golberg, D. Enhanced field emission and optical properties of controlled tapered Zns nanostructures. J. Phys. Chem. C. 116, 8297-8304 (2012).

33 Zhai, T. Y., Fang, X. S., Bando, Y., Dierre, B., Liu, B. D., Zeng, H. B., Xu, X. J., Huang, Y., Yuan, X. L., Sekiguchi, T. \& Goberg, D. Characterization, cathodolumine-scence, and field-emission properties of morphology-tunable cds micro/nanostructures. Adv. Funct. Mater. 19, 2423-2430 (2009).

34 Cui, H., Sun, Y., Yang, G. Z., Chen, J., Jiang, D. \& Wang, C. X. Template- and catalystfree synthesis, growth mechanism and excellent field emission properties of large scale single-crystalline tubular $\beta$-SiC. Chem. Commun. 41, 6243-6245 (2009).

35 Chen, Z., Cao, C. B., Li, W. S. \& Charles, S. Well-aligned single-crystalline GaN nanocolumns and their field emission properties. Cryst. Growth Des. 9, 792-796 (2009).

36 Liu, F., Tian, J. F., Bao, L. H., Yang, T. Z., Shen, C. M., Lai, X. Y., Xiao, Z. M., Xie, W. G., Deng, S. Z., Chen, J., She, J. C., Xu, N. S. \& Gao, H. J. Fabrication of vertically aligned single-crystalline boron nanowire arrays and investigation of their field-emission behavior. Adv. Mater. 20, 2609-2615 (2008).

$37 \mathrm{Xu}$, J. Q., Zhao, Y. M. \& Zhang, Q. Y. Enhanced electron field emission from singlecrystalline LaB6 nanowires with ambient temperature. J. Appl. Phys. 104, 124306 (2008).

38 Jha, M., Patra, R., Ghosh, S. \& Ganguli, A. K. Vertically aligned cerium hexaboride nanorods with enhanced field emission properties. J. Mater. Chem. 22, 6356-6366 (2012).

39 Zhang, H., Tang, J., Yuan, J. S., Ma, J., Shinya, N., Nakajima, K., Murakami, H., Ohkubo, T. \& Qin, L. C. Nanostructured LaB6 field emitter with lowest apical work function. Nano Lett. 10, 3539-3544 (2010).

40 Modinos, A. Field, Thermionic, and secondary electron emission spectroscopy 1-167 (Plenum, New York, 1984).

41 Choueib, M., Ayari, M., Vincent, P., Bachelany, K., Cornu, D. \& Purcell, S. Strong deviations from Fowler-Nordheim behavior for field emission from individual SiC nanowires due to restricted bulk carrier generation. Phys. Rev. B. 79, 075421 (2009).

$42 \mathrm{Kim}$, C., Choi, Y. S., Lee, S. M., Park, J. T., Kim, B. \& Lee, Y. H. The effect of gas adsorption on the field emission mechanism of carbon nanotubes. J. Am. Chem. Soc. 124, 9906-9911 (2002).

43 Dardona, S., Peles, A., Wrobel, G., Piech, M. \& Gao, P. Gas adsorption and high-emission current induced degradation of field emission characteristics in solution-processed ZnO nanoneedles. J. Appl. Phys. 108, 124318 (2010).

(c) (i) (3) $\odot$ This work is licensed under a Creative Commons Attribution-NonCommercial-NoDerivs 3.0 Unported License. To view a copy of this license, visit http://creativecommons. org/licenses/by-nc-nd/3.0/

Supplementary Information accompanies the paper on the NPG Asia Materials website (http://www.nature.com/am) 